\title{
Modified DNA Aptamers for C-Reactive Protein and Lactate Dehydrogenase-5 with Sub-Nanomolar Affinities
}

\author{
Hirotaka Minagawa ${ }^{1}$, Yuka Kataoka ${ }^{2}$, Hiroto Fujita ${ }^{2}$, Masayasu Kuwahara ${ }^{2, *} \mathbb{*}$, \\ Katsunori Horii ${ }^{1}$, Ikuo Shiratori ${ }^{1, *}$ and Iwao Waga ${ }^{1}$ \\ 1 NEC Solution Innovators, Ltd., 1-18-7, Shinkiba, Koto-ku, Tokyo 136-8627, Japan; \\ minagawa-hir@nec.com (H.M.); k-horii@nec.com (K.H.); iwa-waga@nec.com (I.W.) \\ 2 Graduate School of Integrated Basic Sciences, Nihon University, 3-25-40 Sakurajosui, Setagaya-ku, \\ Tokyo 156-8550, Japan; kataoka.yuka@nihon-u.ac.jp (Y.K.); fujita.hiroto@nihon-u.ac.jp (H.F.) \\ * Correspondence: mkuwa@chs.nihon-u.ac.jp (M.K.); shiratori@nec.com (I.S.); \\ Tel.: +81-3-5317-9398 (M.K.); +81-3-5534-2619 (I.S.)
}

Received: 9 March 2020; Accepted: 8 April 2020; Published: 13 April 2020

\begin{abstract}
Human C-reactive protein (CRP) and lactate dehydrogenase are important markers in clinical laboratory testing - the former is used to detect in vivo inflammation, and the latter is used to detect cell necrosis and tissue destruction. We developed aptamers that bind to human CRP and human lactate dehydrogenase-5 (LDH-5) with high affinities (dissociation constants of $6.2 \mathrm{pM}$ and $235 \mathrm{pM}$, respectively), applying the systematic evolution of ligands by exponential enrichment (SELEX) method, and by using a modified DNA library containing the following base-appended base modifications: analog adenine derivative at the fifth position of uracil $\left(\mathrm{U}^{\text {ad }}\right)$, analog guanine derivative at the fifth position of uracil $\left(\mathrm{U}^{\mathrm{gu}}\right)$, and analog adenine derivative at the seventh position of adenine $\left(\mathrm{A}^{\text {ad }}\right)$. A potential application of these aptamers as sensor elements includes high-sensitivity target detection in point-of-care testing.
\end{abstract}

Keywords: C-reactive protein; lactate dehydrogenase; aptamer; base-appended base modification

\section{Introduction}

Aptamers are single-stranded DNA or RNA oligonucleotides that bind to specific molecules or cells [1,2]. Aptamers have similar antibody functions, but are easier to manufacture, and they are advantageous due to low immunogenicity, easy chemical modification, and strong thermal degeneration [3-5]. As such, the development of aptamers as therapeutic and diagnostic agents [6], and as molecule detection devices in biosensors [7], is of current interest.

Aptamers are separated from large nucleic acid combinatorial libraries using an iterative selection process called SELEX (systematic evolution of ligands by exponential enrichment) [8]. In brief, the nucleic acid combinatorial library consists of sequences with a primer and random regions, and the sequence that binds to the target is selected $[9,10]$.

Alternative approaches using a modified nucleic acid library in the SELEX method can improve the probability of detecting candidate aptamers [11]. For instance, SomaLogic Inc. has developed an aptamer called SOMAmer (slow, off-rate, modified aptamer) using uridine derivatives, in which a foreign functional group, such as highly hydrophobic amino acid side chains, is added to the base [12]. Moreover, TAGCyx Biotechnologies has developed aptamers using 7-(2-thienyl)-imidazo [4-b] pyridine (DS)-2-nitro-4-propynylpyrrole (Px) base pairs [13].

In this study, we have developed an alternative method based on base-appended base (BAB) analogs, and successfully isolated aptamers capable of binding to a variety of targets with high 
affinity [14-17]. Human C-reactive protein (CRP) is a main acute-phase protein, and is an important in vivo inflammation marker, as the CRP concentration may increase by more than 1000 -fold in a severe inflammatory state $[18,19]$. Saliva is a biological sample that can be collected non-invasively, and the CRP concentration in saliva was reported to be highly correlated to the CRP concentration in serum $[20,21]$. Despite the low concentration of CRP in saliva, which is approximately $1 / 1600$ of the concentration in the serum [20], this non-invasive procedure is favored for assessing cardiovascular disorders and its association with oral diseases [22,23], and as a marker of pneumonia in infants [24].

Currently, the principal methods for CRP measurement are immunoturbidimetric assay and latex agglutination turbidimetry. Specific monoclonal anti-CRP antibodies are available from commercial sources, and are also used as detection elements in biosensors [25]. However, these antibody-based methods are costly [26]. Lactate dehydrogenase (LDH) is a detectable enzyme in the cytoplasm of nearly all cells in the human body, and its extracellular presence is associated with cell necrosis and tissue destruction, since it becomes extracellular due to cell death [27,28]. LDH is an enzyme whose activity is routinely measured clinically, and it has subtypes ranging from LDH-1 to LDH-5 [29]. The isoenzyme profile of LDH activity is different in the saliva and in the blood: while LDH-5 is dominant in the former, LDH-1 is dominant in the latter [30]. It has been reported that abnormalities of LDH-5 in the saliva are associated with oral squamous cell carcinoma [31,32]. Thus, LDH can serve as an early tumor marker [33]. LDH measurements are mainly based on activity measurement, and anti-LDH antibodies for research applications are available from commercial sources [34]; however, to the best of the authors' knowledge, no diagnostic application based on LDH detection has been developed yet.

In this study, we isolated artificial nucleic acid aptamers with high affinity for CRP and LDH-5, using three types of libraries incorporating BAB modification bases (analog adenine derivative at the fifth position of uracil $\left(U^{\text {ad }}\right)$, analog guanine derivative at the fifth position of uracil $\left(U^{g u}\right)$, and analog adenine derivative at the seventh position of adenine $\left(\mathrm{A}^{\text {ad }}\right)$ ). The aptamer selection was performed utilizing a nucleic acid library with three types of modified nucleic acids, namely $U^{\text {ad }}, U^{g u}$, and $A^{\text {ad }}$ (Figure 1), to obtain CRP-binding and LDH-5-binding aptamers.

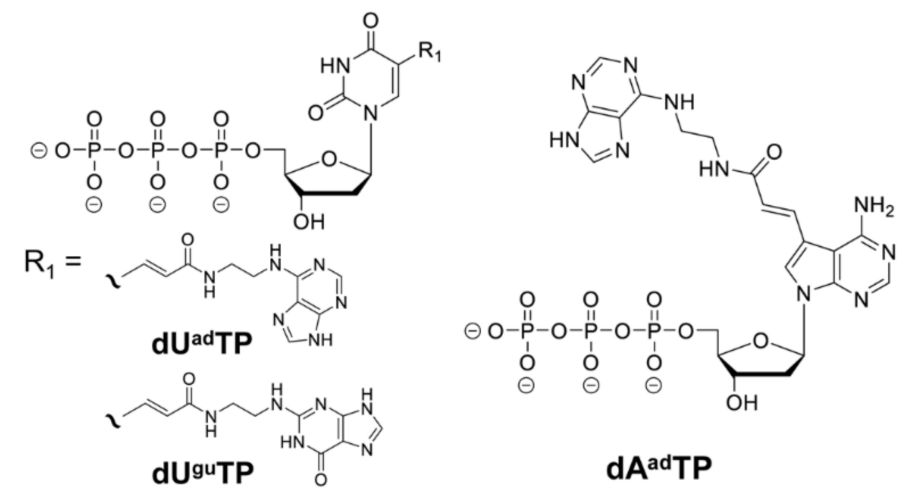

Figure 1. Chemical structures of $\mathrm{dU}^{\mathrm{ad}} \mathrm{TP}, \mathrm{dU}^{\mathrm{gu}} \mathrm{TP}$, and $\mathrm{dA}^{\mathrm{ad}} \mathrm{TP}$.

\section{Results}

In the selection of CRP-binding aptamers, six sequences with more than $5 \%$ sequence ratio were obtained in the Round 8 pool for $U^{\text {ad }}$, six sequences with more than $5 \%$ sequence ratio were obtained in the Round 8 pool for $\mathrm{U}^{\mathrm{gu}}$, and four sequences with more than $5 \%$ sequence ratio were obtained in the Round 8 pool for $\mathrm{A}^{\text {ad }}$ (Table A1). In the selection of LDH-5-binding aptamers, five sequences with more than $5 \%$ sequence ratio were obtained in the Round 8 pool for $\mathrm{Ud}^{\mathrm{ad}}$, four sequences with more than $5 \%$ sequence ratio were obtained in the Round 8 pool for $\mathrm{U}^{\mathrm{gu}}$, and two sequences with more than $5 \%$ sequence ratio were obtained in the Round 8 pool for $\mathrm{A}^{\text {ad }}$ (Table A1).

Target binding assessment was performed using surface plasmon resonance (SPR) on candidate $\mathrm{U}^{\text {ad }}$-, $\mathrm{U}^{\mathrm{gu}}$-, and $\mathrm{A}^{\text {ad }}$-containing aptamers with high sequence ratios. For CRP, six out of the six 
candidate $\mathrm{U}^{\text {ad }}$ sequences and five out of the six candidate $\mathrm{U}^{\mathrm{gu}}$ sequences showed target binding, whereas none of the four candidate $\mathrm{A}^{\text {ad }}$ sequences showed binding (Table 1). Some $\mathrm{U}^{\text {ad }}$ candidate sequences showed binding with secretory immunoglobulin A (SIgA) (Figure A1), a protein molecule that has no association with the sequence or structure of CRP, and thus were removed. The remaining candidates that showed no SIgA binding, namely Ugu2 and Ugu4 (Figure A2), were selected as CRP-binding aptamer candidates for the next step.

Table 1. The sequences from the $\mathrm{U}^{\mathrm{ad}}-$, $\mathrm{U}^{\mathrm{gu}}{ }_{-}$, and $\mathrm{A}^{\mathrm{ad}}$-modified single strand DNA library that target binding assessment was performed using surface plasmon resonance (SPR).

\begin{tabular}{|c|c|c|c|}
\hline Clone Name & $\begin{array}{l}\text { Sequence } \\
\text { Ratio }^{(a)}\end{array}$ & Random Region Sequence ${ }^{(b)}$ & $\begin{array}{l}\text { Average Resonance Unit } \\
\text { (c) for } 400 \mathrm{nM} \text { Target }\end{array}$ \\
\hline CRP-Uad1 & $27.5 \%$ & CGGttACAGAtGAtCAGGCtCAAACAGAtt & 341 \\
\hline CRP-U ${ }^{\text {ad2 }}$ & $24.6 \%$ & AACtGGGtCGAACGCGGttACAGAtGAtCAG & 427 \\
\hline CRP-U ${ }^{\text {ad3 }}$ & $17.4 \%$ & CCttCAAGAAttGCGGttACAGAtGAtCAG & 236 \\
\hline CRP-U & $11.9 \%$ & CCtCGtAtAAGACGGttACAGAtGAtCAGG & 396 \\
\hline CRP-U & $10.7 \%$ & tGAtAAAAGCCCGGttACAGAtGAtCAGGG & 479 \\
\hline CRP-U ${ }^{\text {ad6 }}$ & $7.3 \%$ & ACCGGttACAGAtGAtCAGGGGCAAAGAAC & 249 \\
\hline CRP-Ugu1 & $27.9 \%$ & CAtGAAtGCGtGtGGttAtAGtAttGAACt & 157 \\
\hline CRP-Ugu2 & $14.3 \%$ & GtCtGAAAtCGCtttCCGGAtCGGACttAA & 435 \\
\hline CRP-Ugu3 & $9.6 \%$ & GACGtCCCACGGtttGAtCAAACGtACAtA & 18 \\
\hline CRP-Ugu4 & $6.5 \%$ & CtAGttCtGCCttAAtAtGGtCGGttAAGC & 362 \\
\hline CRP-Ugu5 & $5.9 \%$ & ACtCAAGttAtGCtGGACttCtttACAAAC & 101 \\
\hline CRP-Ugu6 & $5.2 \%$ & GCAtACAACtCCCtAGtCAAACtGACAttA & 93 \\
\hline CRP-A ${ }^{\text {ad1 }}$ & $39.2 \%$ & aаCaTTGaGTGCCaTGCCCTTCGTaGaCa & -53 \\
\hline CRP-A $\mathrm{Ad}^{\text {ad2 }}$ & $19.5 \%$ & TTTaCCGaaTGCCaTGCCCGaGaGTaGaCa & -15 \\
\hline CRP-A $\mathrm{A}^{\text {ad3 }}$ & $10.0 \%$ & TCGaaCGCCaTGCCaCTGCCCGGTTaGaCa & -13 \\
\hline CRP-A $\mathrm{Ad}^{\mathrm{ad}}$ & $5.1 \%$ & aCGTaGCaTaGTGTaaGGaGCGCCCaCTaT & -12 \\
\hline LDH-Uad1 & $8.4 \%$ & CACCCtCCAGACtAtAttCtAGGCAACCGA & 1583 \\
\hline LDH-U $\mathrm{Ud}^{\mathrm{ad}}$ & $7.5 \%$ & tGtGtCGAtCAGAtGCGttACtAAAtCtCA & 1441 \\
\hline LDH-U ${ }^{\text {ad6 }}$ & $4.5 \%$ & tGGGCtAtGGtACtAGACtGGCtCGGttGC & 829 \\
\hline LDH-Ugu1 & $24.3 \%$ & CCtCCGCttGtGGAtACGAtGGACtAGtGG & 1011 \\
\hline LDH-Ugu2 & $12.0 \%$ & ACCttAGACACGGtACttACCGACACtAAA & 862 \\
\hline LDH-Ugu3 & $8.9 \%$ & ttAGAtACttGGCtCtACttAttGACAAtC & 1255 \\
\hline LDH-Ugu4 & $7.3 \%$ & CACtCCtGAttGCttAAGAtCttAGttCGA & 705 \\
\hline $\mathrm{LDH}^{\mathrm{L}} \mathrm{A}^{\mathrm{ad} 1}$ & $55.8 \%$ & CTGCTGGCTCGTGaGaCGGaTaTCaGGTCT & 1415 \\
\hline LDH-A ${ }^{\text {ad2 }}$ & $14.9 \%$ & aGaGGGaGaTCaTCTCTCTGGCGGaCaCaа & 518 \\
\hline
\end{tabular}

$\left({ }^{a}\right)$ Sequence ratio was defined as the ratio of the sequence from the total number of sequences that were generated by next-generation sequencing. $\left({ }^{b}\right)$ Letter " $t$ " indicates the analog adenine derivative at the fifth position of uracil $\left(\mathrm{U}^{\text {ad }}\right)$ or the analog guanine derivative at the fifth position of uracil $\left(\mathrm{U}^{\mathrm{gu}}\right)$, and letter " $\mathrm{A}$ " indicates the analog adenine derivative at the seventh position of adenine $\left(\mathrm{A}^{\mathrm{ad}}\right)$. (c) SPR response units of the interaction between the target and the selected clones. Measurements were performed with either human C-reactive protein (CRP) or lactate dehydrogenase (LDH)-5 (400 nM), injected over the respective aptamer-immobilizing sensor chips for $120 \mathrm{~s}$ at a flow rate of $50 \mu \mathrm{L} / \mathrm{min}$. SPR response units between $115-125 \mathrm{~s}$, which were in the plateau region of the sensorgram curves, were averaged.

For LDH-5, three out of the three candidate $\mathrm{U}^{\text {ad }}$ sequences, four out of the four candidate $\mathrm{U}^{\mathrm{gu}}$ sequences, and two out of the two candidate $\mathrm{A}^{\text {ad }}$ sequences showed target binding (Table 1 ). Since none of the candidate sequences showed any SIgA binding (Figure A3, Figure A4, Figure A5), Ud1, Ugu3, and $\mathrm{A}^{\text {ad1 }}$ are the best ones, because they are the ones with the highest target affinity. Therefore, $\mathrm{Ud}^{\mathrm{ad} 1}$, $\mathrm{Ugu}^{\text {gu }}$, and $\mathrm{A}^{\text {ad1 }}$ were selected as LDH-5-binding aptamer candidates for the next step.

Aptamer-conjugated magnetic beads were produced using the two candidate sequences (Ugu2 and $\mathrm{U}^{\text {gu4 }}$ ) for CRP, and CRP pull-down assays were conducted using purified CRP dissolved in selection buffer (SB; $40 \mathrm{mM}$ 4-(2-hydroxyethyl)-1-piperazineethanesulfonic acid (HEPES), pH7.5, $125 \mathrm{mM} \mathrm{NaCl}$, $5 \mathrm{mM} \mathrm{KCl}, 1 \mathrm{mM} \mathrm{MgCl} 2,0.01 \%$ Tween 20) or a human saliva sample. The results showed that only 
Ugu4 was able to bind CRP in the SB buffer and in the human saliva sample (Figure 2a). This shows that $\mathrm{Ugu}^{\text {gut }}$ can specifically bind to CRP even in the presence of other contaminant proteins, and thus was selected as the final CRP-binding aptamer candidate.

(a)

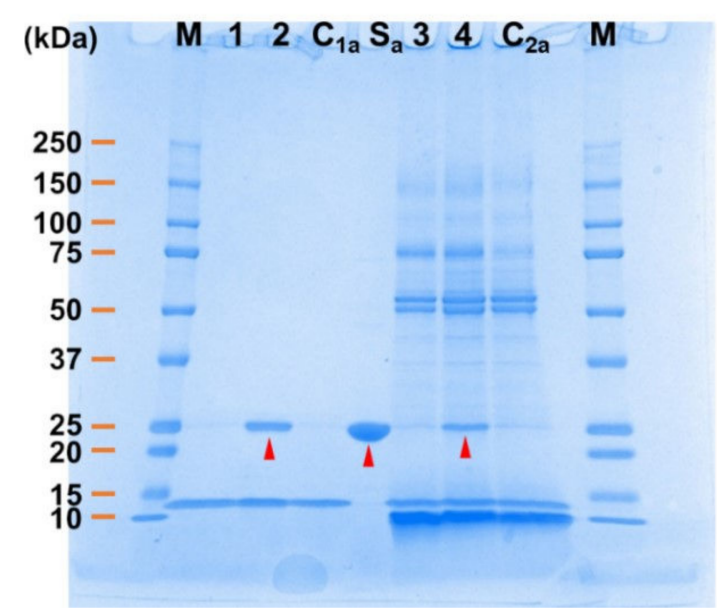

(b)

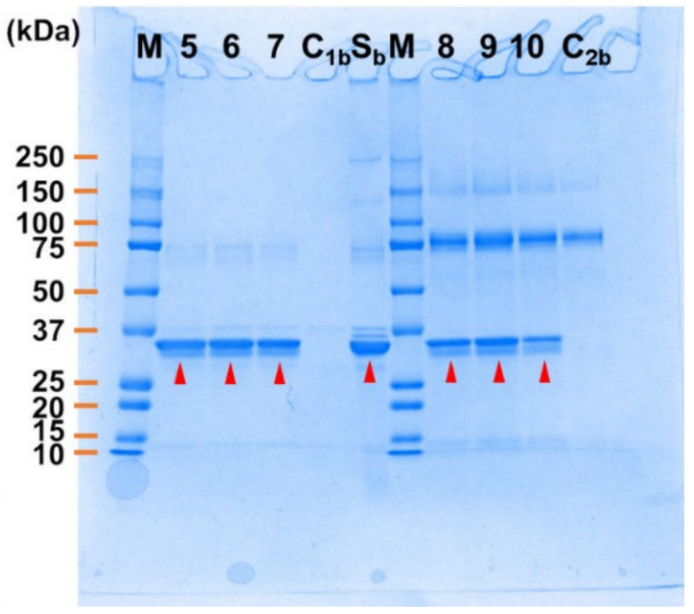

Figure 2. SDS-PAGE image of the samples, representative of the pull-down assay. (a) Pull-down assay using CRP in selection buffer (SB) or human saliva. Lane M: Precision Plus Protein Kaleido Scope Standards (Bio-Rad, United States); Lanes 1-2: CRP in SB sample eluted from the CRP-Ugu2 and $\mathrm{U}^{\text {gu4 }}$-immobilizing CRP capture beads, respectively; Lane $\mathrm{C}_{1 \mathrm{a}}$ : CRP in SB buffer sample eluted from the control beads; Lane $S_{a}$ : CRP; Lanes 3-4: spiked CRP in human saliva sample eluted from the CRP$\mathrm{U}^{\text {gu2 }}$ and $\mathrm{U}^{\text {gu4 }}$-immobilizing CRP capture beads, respectively; Lane $\mathrm{C}_{2 \mathrm{a}}$ : spiked CRP in human saliva sample eluted from the control beads. (b) Pull-down assay using LDH-5 in SB or human saliva. Lane M: Precision Plus Protein Kaleido Scope Standards (Bio-Rad, United States); Lanes 5-7: LDH-5 in SB sample eluted from the LDH-U ${ }^{\text {ad1 }}, \mathrm{U}^{\mathrm{gu} 3}$, and $\mathrm{A}^{\text {ad1 }}$-immobilizing LDH-5 capture beads, respectively; Lane $C_{1 b}$ : LDH-5 in SB buffer sample eluted from the control beads; Lane $S_{b}$ : LDH-5; Lanes 8-10: spiked LDH-5 in human saliva sample eluted from the LDH-U ${ }^{\text {ad1 }}$, Ugu3, and $A^{\text {ad1 }}{ }^{\text {-immobilizing }}$ LDH- 5 capture beads, respectively; Lane $C_{2 b}$ : spiked LDH- 5 in human saliva sample eluted from the control beads.

The same aptamer-conjugated magnetic beads approach was used for LDH-5, to test the three candidate sequences ( $\mathrm{U}^{\mathrm{ad} 1}, \mathrm{U}^{\mathrm{gu} 3}$, and $\mathrm{A}^{\text {ad1 }}$ ). The pull-down assays performed on SB buffer containing purified LDH-5 and a human saliva sample showed that all the candidate sequences were able to bind LDH-5 (Figure $2 b$ ). This shows that $\mathrm{U}^{\text {ad1 }}, \mathrm{U}^{\mathrm{gu} 3}$, and $\mathrm{A}^{\text {ad1 }}$ can bind specifically to LDH-5 in the presence of other contaminant proteins.

The cross-reaction between LDH-1 (LDH- 5 isozyme) and the three LDH- 5 candidate aptamers $\left(\mathrm{U}^{\mathrm{ad} 1}, \mathrm{U}^{\mathrm{gu} 3}\right.$, and $\left.\mathrm{A}^{\mathrm{ad} 1}\right)$ were evaluated using SPR response measurements. In this setting, only $\mathrm{A}^{\text {ad1 }} \mathrm{did}$ not show any LDH-1 binding (Figure A6). The LDH-5 amino acid sequence has $75 \%$ homology with the LDH-1 amino acid sequence, and considering that $\mathrm{A}^{\text {ad1 }}$ had very high LDH- 5 binding specificity, it was selected as the final LDH-5-binding aptamer candidate.

Generally, when the aptamer sequence is long, it is more likely to form various secondary structures that destabilize the conformation of the target binding site of the aptamer [35]. Thus, minimizing the aptamer sequence is a viable strategy to suppress structural instability, thereby improving target-binding strength [36]. Accordingly, sequence minimization for CRP-Ugu4 and $\mathrm{LDH}-\mathrm{A}^{\mathrm{ad} 1}$ was conducted using the SPR measurement as an indicator. Various variant sequences were produced by truncating the $3^{\prime}$ and $5^{\prime}$ ends of the candidate sequences (Figures $3 a$ and $4 a$ ). We successfully shortened the CRP-Ugu4 to a 48 base candidate (CRP-Ugu4-3) (Figure 3b). CRP-Ugu4-3 showed higher CRP-binding avidity (dissociation constant $(\mathrm{Kd})=6.2 \mathrm{pM}$ ) (Figure $3 \mathrm{c}$ ) than the original 
CRP-Ugu4 $(\mathrm{Kd}=53.4 \mathrm{pM})$. In contrast, shortening by truncation of the $3^{\prime}$ end $\left(\mathrm{CRP}-\mathrm{Ugu}^{\text {gu-4}} 4\right)$ resulted in the loss of CRP-binding avidity, even by using the same sequence length of CRP-Ugu4-3 (Figure 3b).

(a)

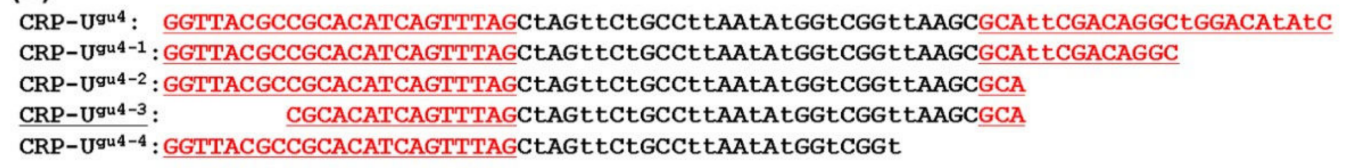

(b)

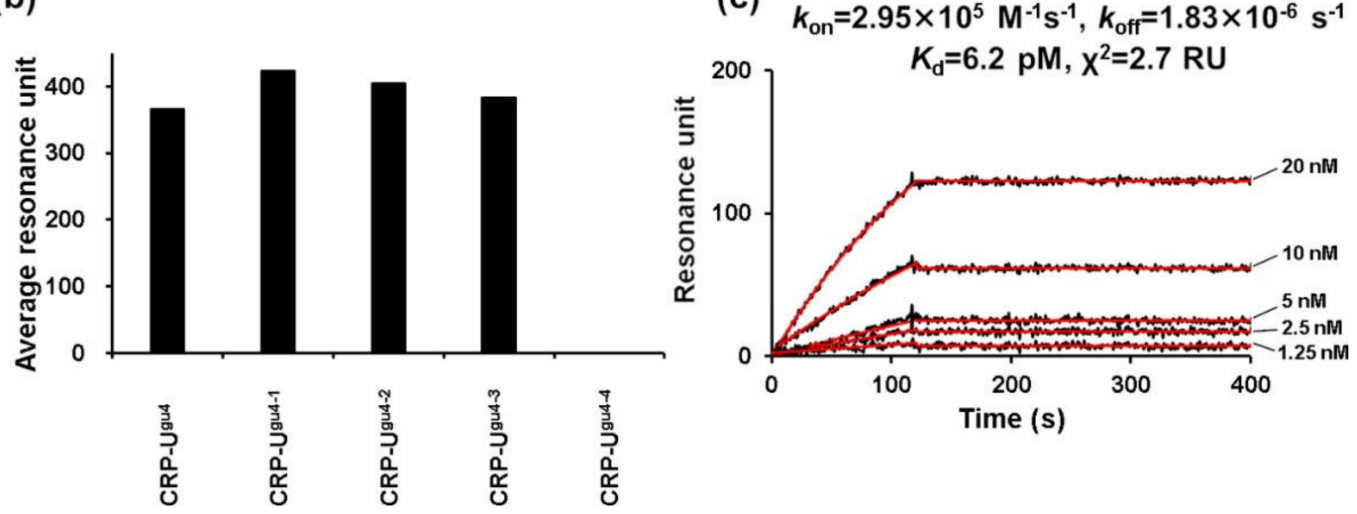

Figure 3. CRP-Ugu4 truncated aptamer preparation. (a) Sequences of the CRP-Ugu4 truncated aptamers. Sequences are aligned in the $5^{\prime}$ to $3^{\prime}$ direction. Underlined regions derive from the primer or

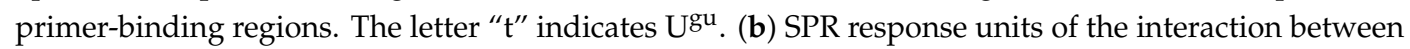
the CRP and the CRP-Ugu4 truncated aptamers. Measurements were performed with multicycle kinetics, and CRP (400 nM) was injected over the respective aptamer-immobilizing sensor chips for $120 \mathrm{~s}$ at a flow rate of $50 \mu \mathrm{L} / \mathrm{min}$. SPR response units between 115-125 s, in the plateau region of the sensorgram curves, were averaged. (c) Representative SPR sensorgrams showing the interaction between the CRP and the aptamer CRP-Ugu4-3. Various concentrations of CRP (1.25-20.00 nM) were injected over the respective CRP-Ugu4-3 The black line represents the measured curve, and the red line represents the fitting curve. The average of the squared differences between the measured data points and the corresponding fitted values are represented as $\chi^{2}$.

We then successfully shortened the LDH-A ${ }^{\text {ad1 }}$ candidate to 44 bases (LDH-A ${ }^{\text {ad1-3 }}$ ) (Figure $4 \mathrm{~b}$ ). LDH-A ${ }^{\text {ad1-3 }}$ showed much higher LDH-5 binding avidity $(\mathrm{Kd}=235 \mathrm{pM})$ (Figure $4 \mathrm{c}$ ) than the original $\mathrm{LDH}-\mathrm{A}^{\mathrm{ad} 1}(\mathrm{Kd}=1.68 \mathrm{nM})$. $\mathrm{LDH}-\mathrm{A}^{\text {ad1-4, }}$, where the primer region at the $3^{\prime}$ end was truncated, showed extremely weak-avidity target-binding (Figure $4 \mathrm{~b}$ ).

The predicted secondary structure of the truncated sequences was compared using the VALFold program [37] and general DNA parameters [38], and using sequences by setting Ugu as "T" and Aad as " $A$ ". The results showed a large difference in predicted secondary structures between CRP-Ugu4_CRP-Ugu4-3 and CRP-Ugu4-4 (Figure A7). Moreover, the predicted secondary structures for LDH-A ${ }^{\text {ad1 }}-\mathrm{LDH}-\mathrm{A}^{\text {ad1-3 }}$ and LDH-A ${ }^{\text {ad1-4 }}$ were also quite different (Figure A8). The results suggest that in CRP-Ugu4-4 and LDH-A ad1-4, the truncation at the $3^{\prime}$ end affected the structure, explaining the loss of target-binding avidity. According to the predicted secondary structure of the truncated sequence of CRP-Ugu4-3 (Figure A9), it could be capable of minimizing the CRP-Ugu4-3 sequence. 
(a)

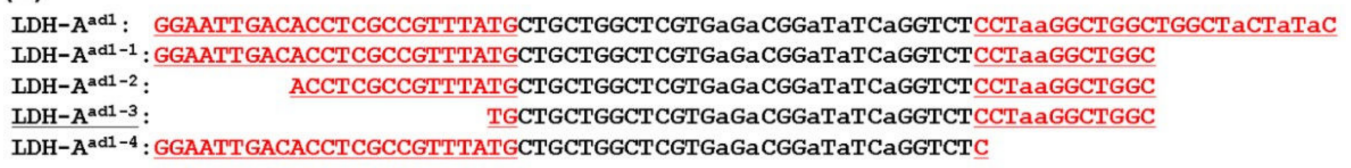

(b)

(c) $k_{\mathrm{on}}=2.63 \times 10^{5} \mathrm{M}^{-1} \mathrm{~s}^{-1}, k_{\mathrm{off}}=6.18 \times 10^{-5} \mathrm{~s}^{-1}$

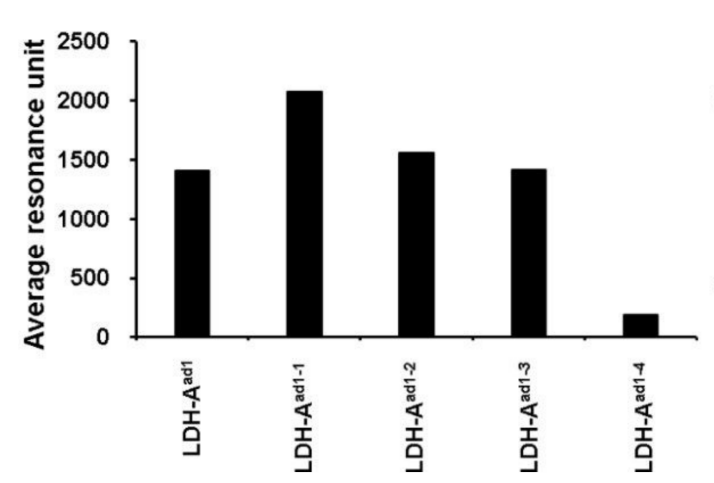
$K_{\mathrm{d}}=235 \mathrm{pM}, \mathrm{X}^{2}=7.2 \mathrm{RU}$

Figure 4. $\mathrm{LDH}-\mathrm{A}^{\mathrm{ad} 1}$ truncated aptamer preparation. (a) Sequences of the LDH-A $\mathrm{A}^{\text {ad } 1}$ truncated aptamers. Sequences are aligned in the $5^{\prime}$ to $3^{\prime}$ direction. Underlined regions derive from the primer or primer-binding regions. The letter " $a$ " indicates $A^{\text {ad }}$. (b) SPR response units of the interaction between the LDH-5 and the LDH-A ${ }^{\text {ad1 }}$ truncated aptamers. Measurements were performed with multicycle kinetics, and LDH (400 nM) was injected over the respective aptamer-immobilizing sensor chips for $120 \mathrm{~s}$ at a flow rate of $50 \mu \mathrm{L} / \mathrm{min}$. SPR response units between 115-125 s, which were in the plateau region of the sensorgram curves, were averaged. (c) Representative SPR sensorgrams showing the interaction between the LDH-5 and the aptamer LDH-A ${ }^{\text {ad1-3 }}$. Various concentrations of LDH-5 $(1.25-20.00 \mathrm{nM})$ were injected over the respective $\mathrm{LDH}-\mathrm{A}^{\text {ad1-3 }}$-immobilizing sensor chip for $120 \mathrm{~s}$ at a flow rate of $50 \mu \mathrm{L} / \mathrm{min}$. The black line represents the measured curve, and the red line represents the fitting curve. The average of the squared differences between the measured data points and the corresponding fitted values are represented as $\chi^{2}$.

\section{Discussion}

The aptamers isolated using the three types of base-appended base approach $\left(\mathrm{U}^{\mathrm{ad}}, \mathrm{U}^{\mathrm{gu}}\right.$, and $\mathrm{A}^{\mathrm{ad}}$; Figure 1), showed quite different characteristics. For CRP, we successfully obtained binding sequences with $U^{\text {ad }}$ and $U^{\text {gu }}$, whereas with $A^{\text {ad }}$, although sequences with high sequence ratios were retrieved, we found no sequence capable of binding CRP (Table 1).

Aptamers for CRP have been previously obtained using natural bases [39-41] and modified bases [42], but the binding regions on the protein have not been reported. Analysis of the CRP crystal structure revealed that there is a positively charged region outside the groove at the bottom of Asp112, which is an important residue for the recognition of complement C1q by CRP [43]. The binding sites of the aptamers isolated in this study are currently unknown, but aptamers, which are negatively charged, usually bind easily to positively-charged regions. Considering this, it is likely that, in the case of $\mathrm{A}^{\text {ad }}$, the volume of the modified site was larger $\mathrm{U}^{\text {ad }}$ and $\mathrm{U}^{\mathrm{gu}}$, and thus appropriate sequences that fit the groove structure could not be obtained.

On the other hand, for LDH-5, binding sequences with $U^{\text {ad }}, U^{\text {gu }}$, and $A^{\text {ad }}$ were obtained, and all candidate sequences showed strong LDH-5-binding. Since LDH-5 has a substructure that interacts with dinucleotides like FADH and NADH, called a Rossmann-type fold [44], the binding to the modified $\mathrm{U}^{\mathrm{ad}}, \mathrm{U}^{\mathrm{gu}}$, and $\mathrm{A}^{\text {ad }}$ may have been easier

A previous study reported the isolation of LDH-binding aptamers [45], but their sequence and target specificity were not elucidated. The aptamers obtained in this study can distinguish between LDH isozymes, and could be potentially be used as tools for the early diagnosis of oral cancer [46]. 
The aptamers obtained in this study have sufficient potentials for detecting endogenous target molecules, according to their dissociation constants and high binding specificity. No detectable pull-down can be observed for non-spiked human saliva, because the concentrations of endogenous target molecules are below the limitation of Coomassie stain [23]. Thus, we spiked the saliva samples with recombinant analytes as a validation of binding, and showed specific bindings of the aptamers. Application of electrochemical sensing [47], acoustic sensing [48], or thermal sensing [49] may lead to highly sensitive target detection in such testing, as point-of-care testing [50,51].

\section{Materials and Methods}

\subsection{Materials}

Purified CRP was purchased from OriGene Technologies Inc. (Rockville, Maryland, United States), and purified LDH-5 was purchased from Meridian Life Science Inc. (Tennessee, United States). Purified LDH-1 isoenzyme was purchased from RayBiotech Life, United States. Magnetic beads for the immobilization of the target and recovery of biotinylated DNA-namely, Dynabeads MyOne Carboxylic Acid magnetic beads, and Dynabeads MyOne SA C1 magnetic beads-were purchased from Invitrogen (Carlsbad, CA, United States). KOD Dash (TOYOBO, Japan) was used for PCR and incorporating modified bases. Synthetic compounds used as primers, random pools, and aptamer clone templates were purchased from Integrated DNA Technologies MBL KK (IDT-MBL KK, Japan). Research grade materials were used for other reagents. The $\mathrm{dU}^{\mathrm{ad}} \mathrm{TP}, \mathrm{d} \mathrm{U}^{\mathrm{gu}} \mathrm{TP}$, and $\mathrm{dA}^{\mathrm{ad}} \mathrm{TP}$ were synthesized using previously reported methods $[17,52,53]$.

\subsection{SELEX}

The SELEX method was performed as previously described [16]. CRP or LDH-5 was bound to Dynabeads MyOne Carboxylic Acid magnetic beads following the manufacturer's instructions, and was washed with selection buffer (SB; $40 \mathrm{mM}$ HEPES, pH7.5, $125 \mathrm{mM} \mathrm{NaCl}$, $5 \mathrm{mM} \mathrm{KCl}, 1 \mathrm{mM} \mathrm{MgCl} 2,0.01 \%$ Tween 20), to produce the target beads. dsDNA incorporating $\mathrm{U}^{\text {ad }}, \mathrm{U}^{\text {gu }}$, or $\mathrm{A}^{\text {ad }}$ was produced using complementary strands with $5^{\prime}$-biotin modification (CRP: GATATGTCCAGCCTGTCGAATG C-N ${ }_{30}$-CTAAACTGATGTGCGGCGTAACC, LDH-5: GTATAGTAGCCAGCCAGCCTTAGG-N30-CATAAACGGCGAGGTGTCAATTCC), forward (Fw) primer (CRP: GGTTACGCCGCACATCAGT TTAG, LDH-5: GGAATTGACACCTCGCCGTTTATG). After binding the dsDNA to Dynabeads MyOne SA C1 magnetic beads, single strand DNA was eluted using $0.02 \mathrm{M} \mathrm{NaOH}$ and neutralized with $0.08 \mathrm{M} \mathrm{HCl}$, to produce the ssDNA $U^{\text {ad }}$, Ugu, and $\mathrm{A}^{\text {ad }}$ libraries.

After mixing $80 \mathrm{pmol}$ of the library to $250 \mu \mathrm{g}$ of target beads for $15 \mathrm{~min}$ at $25^{\circ} \mathrm{C}$, and washing the beads with SB, the bead-bound ssDNA was eluted with $7 \mathrm{M}$ urea. The eluted ssDNA was amplified by PCR using the Fw primer and biotin-modified reverse (Rv) primers. The amplified dsDNA was bound to Dynabeads MyOne SA C1 magnetic beads, and after elution of the Fw chain with $0.02 \mathrm{M} \mathrm{NaOH}$, the beads were washed with SB. The ssDNA produced by this method, using the Rv chain and Fw primer, and either $\mathrm{U}^{\text {ad }}{ }_{-}$, or $\mathrm{U}^{\mathrm{gu}}{ }_{-}$, or $\mathrm{A}^{\text {ad }}$ immobilized in magnetic beads, was used in the next round. After eight rounds of selection, PCR was performed using the Fw primer and non-biotin-modified Rv primer, and sequencing was performed using a GS junior sequencer (Roche, Indianapolis, United States)

\subsection{Surface Plasmon Resonance (SPR) Assay}

All SPR measurements were performed at $25^{\circ} \mathrm{C}$ using the ProteON XPR360 instrument (Bio-Rad Laboratories, Inc., Hercules, United States) [16]. For the $U^{\text {ad }}$ and $U^{g u}$ aptamer clones, the ligand was set by appending poly- $\mathrm{A}_{20}$ at the $3^{\prime}$ end, and by hybridization of the $5^{\prime}$ end bound to an NLC sensor chip with biotin-modified oligo $\left(\mathrm{dT}_{20}\right)[16,17]$. For the $\mathrm{A}^{\text {ad }}$ aptamer clones, the ligand was set by appending poly- $\mathrm{T}_{20}$ at the $3^{\prime}$ end, and by hybridization of the $5^{\prime}$ end bound to NLC sensor chip with biotin-modified oligo $\left(\mathrm{dA}_{20}\right)$ [53]. Either CRP or LDH-5 was used as an ananalyte, and SB 
was used as the running buffer. The dissociation constant was calculated by simple 1:1 biomolecular interaction model that is the most common kinetic fit model used for SPR data analysis, following the device instructions.

\subsection{Pull-Down Assay}

The pull-down assay using magnetic beads was performed by using a modified version of the method described in [17]. Clones ( $350 \mathrm{pmol}$ ) synthesized using the $5^{\prime}$ end biotinylated Fw primer, a non-biotin-modified template, and $3 \mathrm{mg}$ of Dynabeads MyOne SA C1 magnetic beads, were mixed in $\mathrm{SB}\left(25^{\circ} \mathrm{C}, 30 \mathrm{~min}\right)$. Then, the beads were washed three times with SB. Next, after eluting the template with $20 \mathrm{mM} \mathrm{NaOH}$, the beads were washed three times with SB and then suspended in $300 \mu \mathrm{L}$ of SB. Clone beads $(250 \mu \mathrm{g})$ and CRP or LDH-5 $(2 \mu \mathrm{g})$ were mixed in SB at $25^{\circ} \mathrm{C}$ for $60 \mathrm{~min}$. In parallel, a sample of $88 \%$ of human saliva was supplemented with $2 \mu \mathrm{g}$ of CRP or LDH- 5 at $25^{\circ} \mathrm{C}$ for $60 \mathrm{~min}$. The supernatant was removed, and after washing the beads with SB three times, the protein bound to the beads was agitated in a $2 \%$ SDS solution at room temperature for $10 \mathrm{~min}$, to elute the synthetic compound bound to the beads. Electrophoresis was performed with the eluted sample using PAGEL C520L (ATTO, Tokyo, Japan) following the manufacturer's instructions.

\section{Conclusions}

In this study, we obtained aptamers with an extremely high binding avidity for CRP and LDH-5, by applying selection using three types of BAB-modified DNA libraries ( $\mathrm{dU}^{\mathrm{ad}} \mathrm{TP}, \mathrm{dU}^{\mathrm{gu}} \mathrm{TP}$, and $\left.\mathrm{dA}^{\mathrm{ad}} \mathrm{TP}\right)$. The best minimized CRP aptamer (CRP-Ugu4-3, 48 mer) binds strongly to CRP $\left(K_{\mathrm{d}}=6.2 \mathrm{pM}\right)$, and the best minimized LDH-5 aptamer (LDH-A ${ }^{\text {ad1 }}-3,44$ mer) also binds strongly to LDH-5 $\left(K_{d}=235 \mathrm{pM}\right)$. To the best of our knowledge, this is the first report fully characterizing LDH- 5 binding aptamers. the obtained LDH-5 aptamers have high specificity and the ability to distinguish between highly homologous isozymes. These aptamers could be useful as biosensor elements with an electrochemical base of the target analyte.

Author Contributions: Conceptualization, I.S. and M.K.; methodology, H.M., Y.K., and H.F.; validation, H.M., Y.K., and H.F.; formal analysis, H.M.; investigation, H.M.; resources, H.M., Y.K., and H.F.; data curation, H.M.; writing-original draft preparation, H.M.; writing-review and editing, I.S. and M.K.; visualization, H.M.; supervision, K.H.; project administration, I.S. and M.K.; funding acquisition, I.W. All authors have read and agreed to the published version of the manuscript.

Funding: This study was partly supported by a grant from the Adaptable and Seamless Technology Transfer Program through Target-Driven R\&D, no. AS2525029M, from the Japan Science and Technology Agency (JST), and by the Basic Science and Platform Technology Program for Innovative Biological Medicine, no. JP18am0301026, from the Japan Agency for Medical Research and Development (AMED).

Conflicts of Interest: The authors declare no conflict of interest. The funders had no role in the design of the study; in the collection, analyses, or interpretation of data; in the writing of the manuscript, or in the decision to publish the results.

$\begin{array}{ll}\text { Abbreviations } \\ \text { CRP } & \text { C-reactive protein } \\ \text { LDH } & \text { Lactate dehydrogenase } \\ \text { SELEX } & \text { Systematic evolution of ligands by exponential enrichment } \\ \text { BAB } & \text { Base-appended base } \\ \text { SB } & \text { Selection buffer } \\ \text { SIgA } & \text { Secretory immunoglobulin A } \\ \text { FW } & \text { Forward } \\ \text { Rv } & \text { Reverse } \\ \text { SPR } & \text { Surface plasmon resonance }\end{array}$


Appendix A

Table A1. The 10 most common sequences in the $\mathrm{U}^{\mathrm{ad}}{ }_{-}, \mathrm{U}^{\mathrm{gu}}{ }_{-}$, and $\mathrm{A}^{\mathrm{ad}}-$ modified ssDNA libraries.

\begin{tabular}{|c|c|c|c|c|c|}
\hline Clone Name & Sequence Ratio ${ }^{(a)}$ & Random Region Sequence ${ }^{(b)}$ & Clone Name & Sequence Ratio ${ }^{\text {(a) }}$ & Random Region Sequence ${ }^{(b)}$ \\
\hline CRP-Uad1 & $27.5 \%$ & CGGttACAGAtGAtCAGGCtCAAACAGAtt & LDH-U ${ }^{\text {ad1 }}$ & $8.4 \%$ & CACCCtCCAGACtAtAttCtAGGCAACCGA \\
\hline CRP-U ${ }^{\text {ad2 }}$ & $24.6 \%$ & AACtGGGtCGAACGCGGttACAGAtGAtCAG & LDH-U ${ }^{\text {ad2 }}$ & $7.5 \%$ & tGtGtCGAtCAGAtGCGttACtAAAtCtCA \\
\hline CRP-U ${ }^{\text {ad3 }}$ & $17.4 \%$ & CCttCAAGAAttGCGGttACAGAtGAtCAG & LDH-U ${ }^{\mathrm{ad} 3}$ & $6.9 \%$ & AGGCCtCCCtCCtAtAttCtAGGCGACCGA \\
\hline CRP-U ${ }^{\text {ad } 4}$ & $11.9 \%$ & CCtCGtAtAAGACGGttACAGAtGAtCAGG & LDH-U ${ }^{\text {ad4 }}$ & $6.2 \%$ & CCGGtAACACtAAtGtGAAtCtGACtAtAt \\
\hline CRP-Uad5 & $10.7 \%$ & tGAtAAAAGCCCGGttACAGAtGAtCAGGG & LDH-U $\mathrm{U}^{\mathrm{ad} 5}$ & $5.3 \%$ & CAtCCACtACGCCtAtAttCtAGGCGACCGA \\
\hline CRP-Uad6 & $7.3 \%$ & ACCGGttACAGAtGAtCAGGGGCAAAGAAC & LDH-Uad6 & $4.5 \%$ & tGGGCtAtGGtACtAGACtGGCtCGGttGC \\
\hline CRP-U ${ }^{\text {ad7 }}$ & $0.13 \%$ & AtCGAAttGCtGGttACGGCAtCGAtCAGA & LDH-U ${ }^{\text {ad7 }}$ & $2.7 \%$ & GtAACACtAAtCtCCCACCtCCCGtAtAtC \\
\hline CRP-U & $0.04 \%$ & ACCGGttACAGAtGAtCAGGG & $\mathrm{LDH}-\mathrm{U}^{\mathrm{ad} 8}$ & $2.5 \%$ & GtCGGttttCGCGtGGAGGtCCGtGAtCGG \\
\hline CRP-Uad9 & $0.01 \%$ & AttGCtttAtGCCGGttACtGAtGAtCAGG & LDH-Uad9 & $2.4 \%$ & GGGtAttGGtCtCGACCACCGCtCGGAACC \\
\hline CRP-U ${ }^{\text {ad10 }}$ & $0.01 \%$ & AAtACGCtAtCCGtGtGCAGtCCGAAtGAt & LDH-U ${ }^{\text {ad10 }}$ & $2.2 \%$ & tGtGtCGAtCAGAtGCGttACtAAtCtCA \\
\hline CRP-Ugu1 & $27.9 \%$ & CAtGAAtGCGtGtGGttAtAGtAttGAACt & LDH-Ugu1 & $24.3 \%$ & CCtCCGCttGtGGAtACGAtGGACtAGtGG \\
\hline CRP-Ugu2 & $14.3 \%$ & GtCtGAAAtCGCtttCCGGAtCGGACttAA & LDH-Ugu2 & $12.0 \%$ & ACCttAGACACGGtACttACCGACACtAAA \\
\hline CRP-Ugu3 & $9.6 \%$ & GACGtCCCACGGtttGAtCAAACGtACAtA & LDH-Ugu3 & $8.9 \%$ & ttAGAtACttGGCtCtACttAttGACAAtC \\
\hline CRP-Ugu4 & $6.5 \%$ & CtAGttCtGCCttAAtAtGGtCGGttAAGC & LDH-Ugu4 & $7.3 \%$ & CACtCCtGAttGCttAAGAtCttAGttCGA \\
\hline CRP-Ugu5 & $5.9 \%$ & ACtCAAGttAtGCtGGACttCtttACAAAC & LDH-Ugu5 & $3.2 \%$ & tGtCttGGACACGGtACttACCtCACACtA \\
\hline CRP-Ugu6 & $5.2 \%$ & GCAtACAACtCCCtAGtCAAACtGACAttA & LDH-Ugu6 & $2.5 \%$ & AtGtCCCttGGCtAtAGttCAAGtttAGAA \\
\hline CRP-Ugu7 & $3.9 \%$ & GtCtGAAAtCAAtCtCGAttCGGAAttAtG & LDH-Ugu7 & $2.5 \%$ & GACACAtACttGGCtCtACAtAttGAGAGA \\
\hline CRP-Ugu8 & $3.5 \%$ & AGAttCAGACCCCGAGGtAAtGCCGACtGt & LDH-Ugu8 & $1.6 \%$ & GGAGAtACttGGCtCtACttAttGACAAtC \\
\hline CRP-Ugu9 & $3.6 \%$ & GAtGCGGtCtGAAAtCAAtCtAAAttCGCG & LDH-Ugu9 & $1.3 \%$ & ACCttCGACACGGtACttACCGACACtAAA \\
\hline CRP-Ugu10 & $2.6 \%$ & GAACGGCtGCAtCCCCtAGtGGtGtAGGCA & LDH-Ugu10 & $1.2 \%$ & tAAGAtACttGGCtCtACttAttGACAAtC \\
\hline CRP-A ${ }^{\text {ad1 }}$ & $39.2 \%$ & aaCaTTGaGTGCCaTGCCCTTCGTaGaCa & LDH-A ${ }^{\text {ad1 }}$ & $55.8 \%$ & CTGCTGGCTCGTGaGaCGGaTaTCaGGTCT \\
\hline CRP-A ${ }^{\text {ad2 }}$ & $19.5 \%$ & TTTaCCGaaTGCCaTGCCCGaGaGTaGaCa & LDH-A ${ }^{\text {ad2 }}$ & $14.9 \%$ & aGaGGGaGaTCaTCTCTCTGGCGGaCaCaa \\
\hline CRP-A ${ }^{\text {ad3 }}$ & $10.0 \%$ & TCGaaCGCCaTGCCaCTGCCCGGTTaGaCa & LDH-A ${ }^{\text {ad3 }}$ & $1.9 \%$ & CTGCTGGTTCGTGaGaCGGaTaTCaGGTCT \\
\hline CRP-A ${ }^{\text {ad4 }}$ & $5.1 \%$ & aCGTaGCaTaGTGTaaGGaGCGCCCaCTaT & LDH-A ${ }^{\text {ad4 }}$ & $1.9 \%$ & CTaCTGGCTCGTGaGaCGGaTaTCaGGTCT \\
\hline CRP-A ${ }^{\text {ad5 }}$ & $4.2 \%$ & CaGCCGCCTGCCaTGCCCCCGCGGTaGaCa & LDH-A ${ }^{\text {ad5 }}$ & $1.8 \%$ & CCGaCTCTaTGTGaGaGGGaGaTCaGCTCT \\
\hline CRP-A ${ }^{\text {ad } 6}$ & $3.5 \%$ & CaaaGTTaGGTGCTCCGTaCaCCaCTCTGC & LDH-A ${ }^{\text {ad6 }}$ & $1.2 \%$ & CTGCTGGCTTGTGaGaCGGaTaTCaGGTCT \\
\hline CRP-A ${ }^{\text {ad7 }}$ & $3.3 \%$ & aaGaCaaTTGCCaTGCCCCCGTaGTaGaCa & LDH-A ${ }^{\text {ad7 }}$ & $0.9 \%$ & CTGCTaGCTCGTGaGaCGGaTaTCaGGTCT \\
\hline CRP-A ${ }^{\text {ad8 }}$ & $2.9 \%$ & CaTGGCCaTGTCCCCCGGTaGaCaGCCGaT & LDH-A ${ }^{\text {ad} 8}$ & $0.7 \%$ & aGaGGGaGaTCaTCTCTCTGGCGGaCaTaа \\
\hline CRP-A ${ }^{\text {ad } 9}$ & $2.3 \%$ & aaCCaaaTGCCaTGCCCCTCaGGTaGaCa & LDH-A ${ }^{\text {ad } 9}$ & $0.7 \%$ & aGaCGGaTaGCaTGTCTCTGGCTGTGaTGT \\
\hline CRP-A ${ }^{\text {ad10 }}$ & $1.6 \%$ & TaTGTCGTaTGCCaTGCCCTGGaGTaGaCa & LDH-A ${ }^{\text {ad10 }}$ & $0.7 \%$ & CTGCTGaCTCGTGaGaCGGaTaTCaGGTCT \\
\hline
\end{tabular}

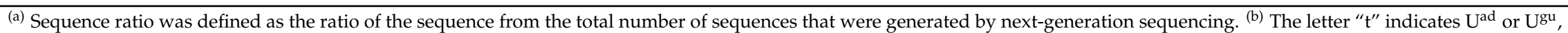
and the letter "a" indicates Ad. 

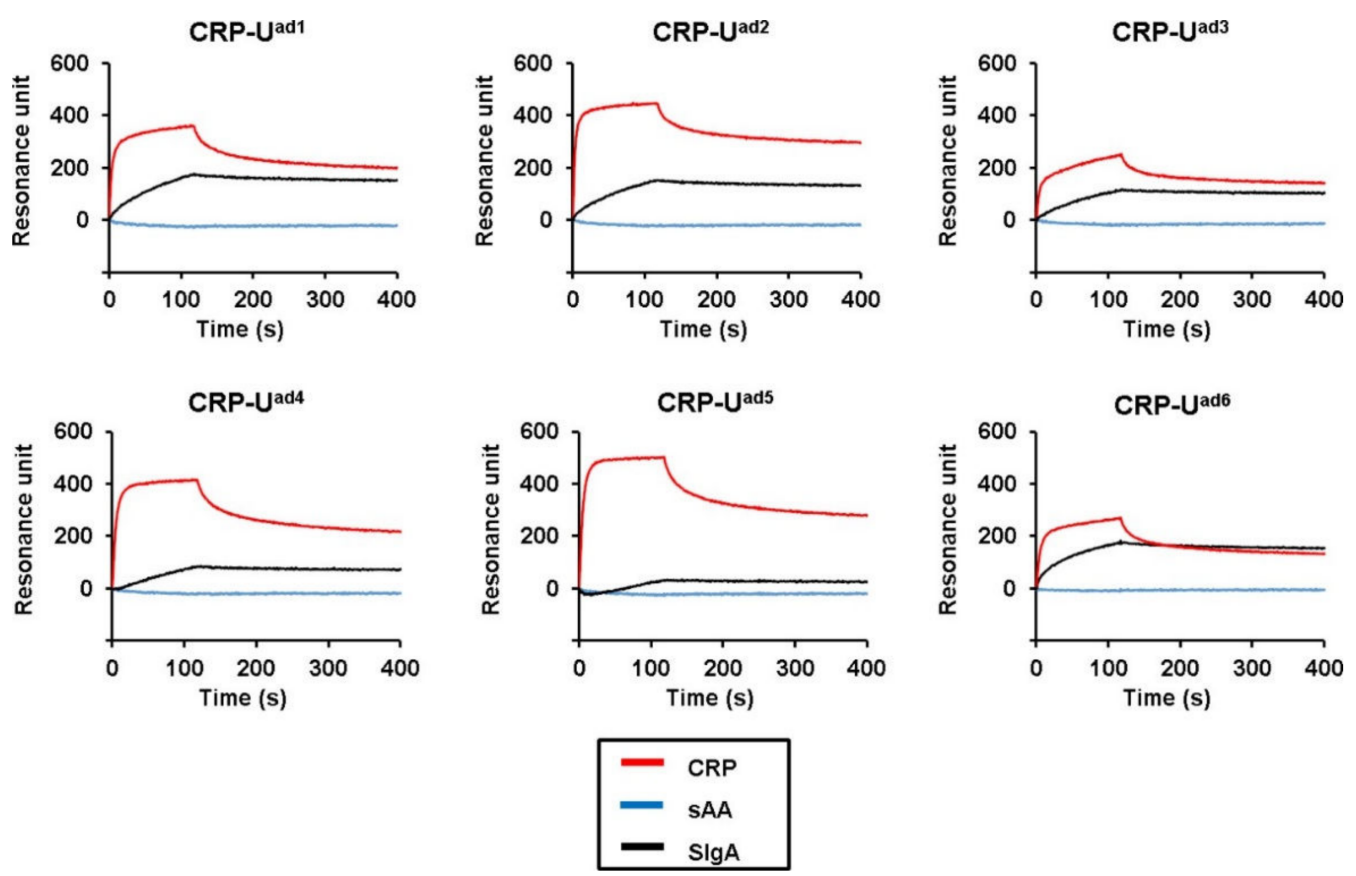

Figure A1. SPR response curve of the interaction between either CRP, salivary protein secretory immunoglobulin A (SIgA), or salivary $\alpha$-amylase (sAA)) and the candidate aptamers CRP-Uad1, $U^{\text {ad2 }}$, $\mathrm{U}^{\mathrm{ad} 3}, \mathrm{U}^{\mathrm{ad} 4}, \mathrm{U}^{\mathrm{ad} 5}$, and $\mathrm{U}^{\mathrm{ad} 6}$. CRP, SIgA, or sAA (400 $\mathrm{nM}$ each) were injected over the respective aptamer-immobilizing sensor chips for $120 \mathrm{~s}$ at a flow rate of $50 \mu \mathrm{L} / \mathrm{min}$. The red line represents the CRP measured curve, while the blue and black lines represent the sAA and SIgA recorded curves, respectively.
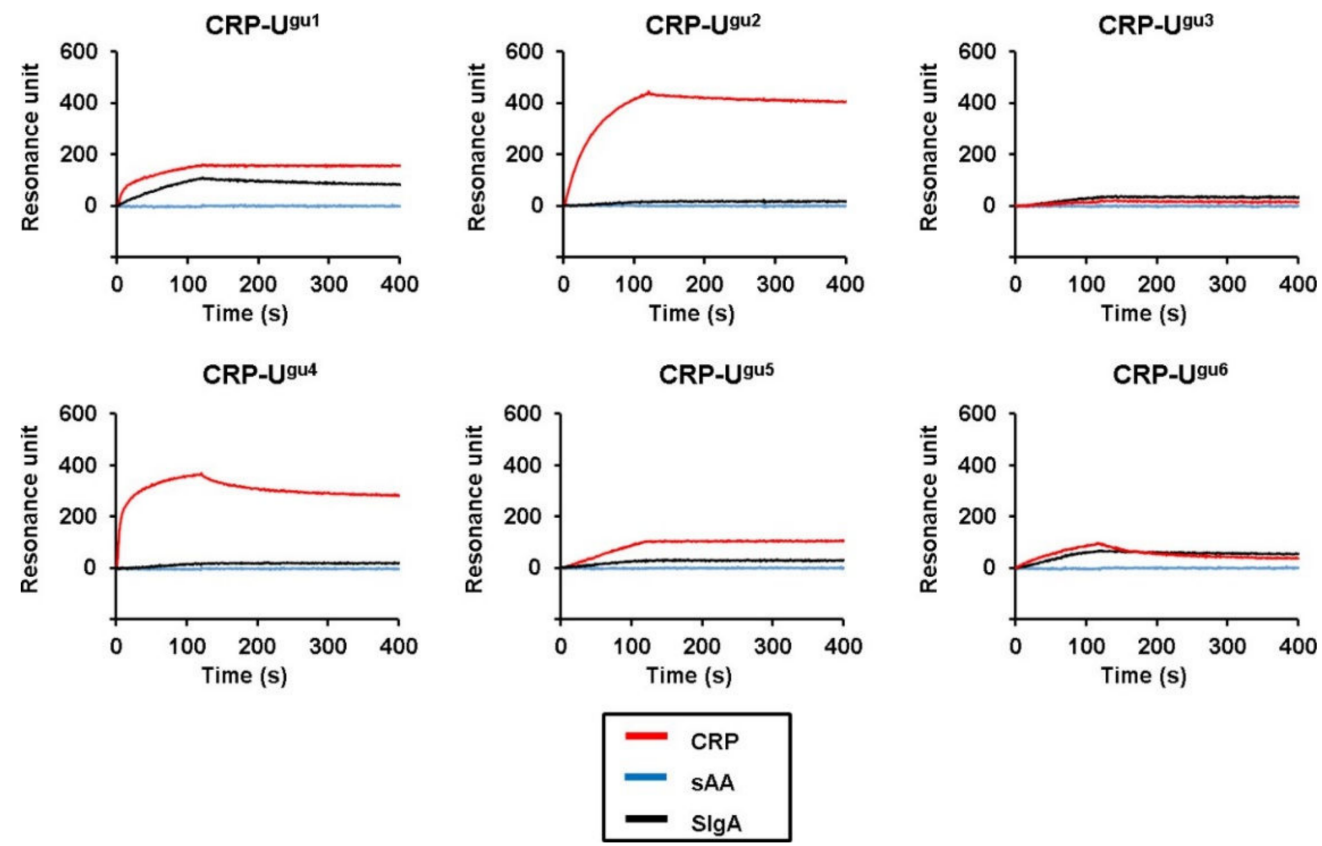

Figure A2. SPR response curve of the interaction between either CRP or the salivary proteins SIgA and sAA, and the candidate aptamers CRP-Ugu1, Ugu2, Ugu3, Ugu4, Ugu5, and Ugu6. CRP, SIgA, or sAA (400 $\mathrm{nM}$ each) were injected over the respective aptamer-immobilizing sensor chips for $120 \mathrm{~s}$ at a flow rate of $50 \mu \mathrm{L} / \mathrm{min}$. The red line represents the CRP measured curve, while the blue and black lines represent the sAA and SIgA recorded curves, respectively. 
LDH-Uad1

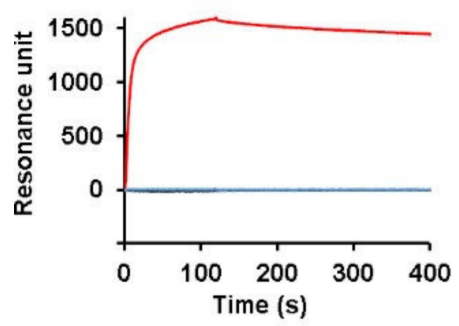

LDH-Uad2

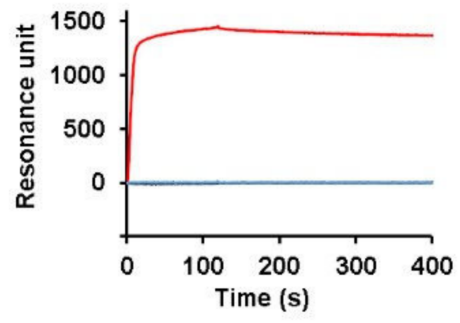

$$
\begin{aligned}
& - \text { LDH-5 } \\
& - \text { sAA } \\
& -\quad \text { SIgA }
\end{aligned}
$$

LDH-Uad6

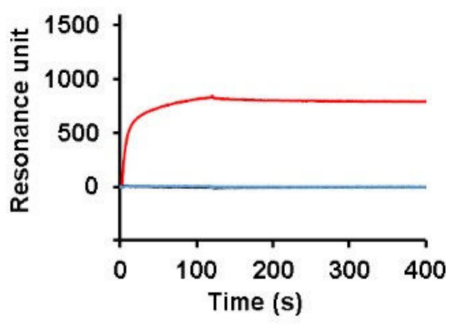

Figure A3. SPR response curve of the interaction between either LDH-5 or the salivary proteins SIgA and sAA and the candidate aptamers LDH-Uad1, $U^{\text {ad2 }}$, and $U^{\text {ad6 }}$. LDH-5, SIgA, or sAA (400 nM each) were injected over the respective aptamer-immobilizing sensor chips for $120 \mathrm{~s}$ at a flow rate of $50 \mu \mathrm{L} / \mathrm{min}$. The red line represents the LDH- 5 measured curve, while the blue and black lines represent the sAA and SIgA recorded curves, respectively.

LDH-Ugu1

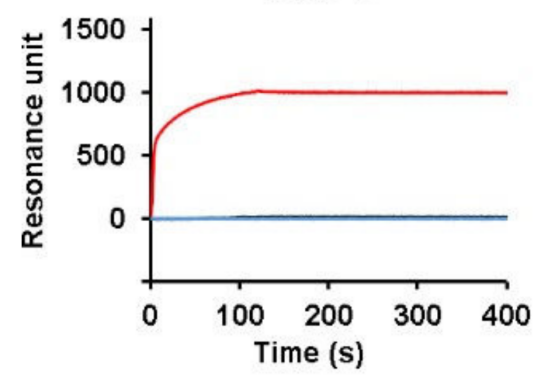

LDH-Ugu3

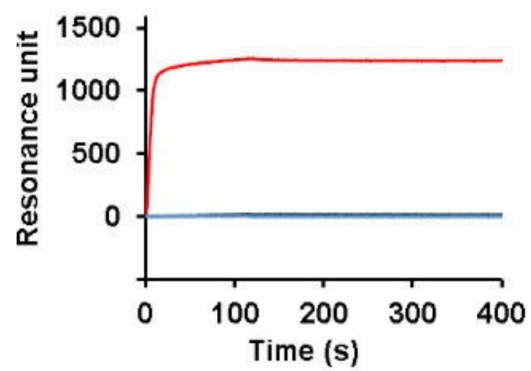

LDH-Ugu2

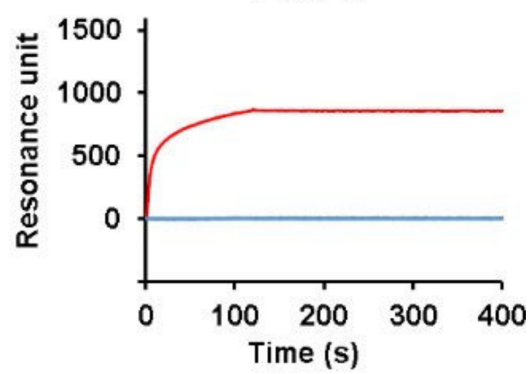

LDH-Ugu4

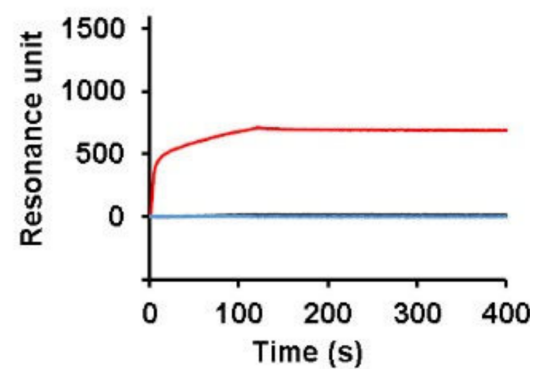

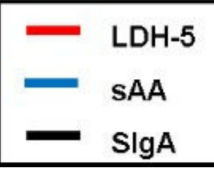

Figure A4. SPR response curve of the interaction between either LDH-5 or the salivary proteins SIgA and sAA, and the candidate aptamers LDH-Ugu1, Ugu2, Ugu3, and Ugu4. LDH-5, SIgA, or sAA (400 nM) were injected over the respective aptamer-immobilizing sensor chips for $120 \mathrm{~s}$ at a flow rate of $50 \mu \mathrm{L} / \mathrm{min}$. The red line represents the LDH-5 measured curve, while the blue and black lines represent the sAA and SIgA recorded curves, respectively. 

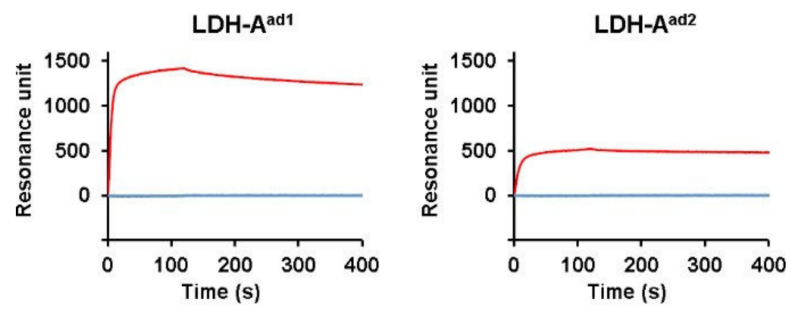

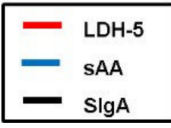

Figure A5. SPR response curve of the interaction between either LDH-5 or the salivary proteins SIgA and SAA, and the candidate aptamers LDH-A ad1 and Ad2. LDH-5, SIgA, or sAA (400 nM each) were injected over the respective aptamer-immobilizing sensor chips for $120 \mathrm{~s}$ at a flow rate of $50 \mu \mathrm{L} / \mathrm{min}$. The red line represents the LDH-5 measured curve, while the blue and black lines represent the sAA and SIgA recorded curves, respectively.
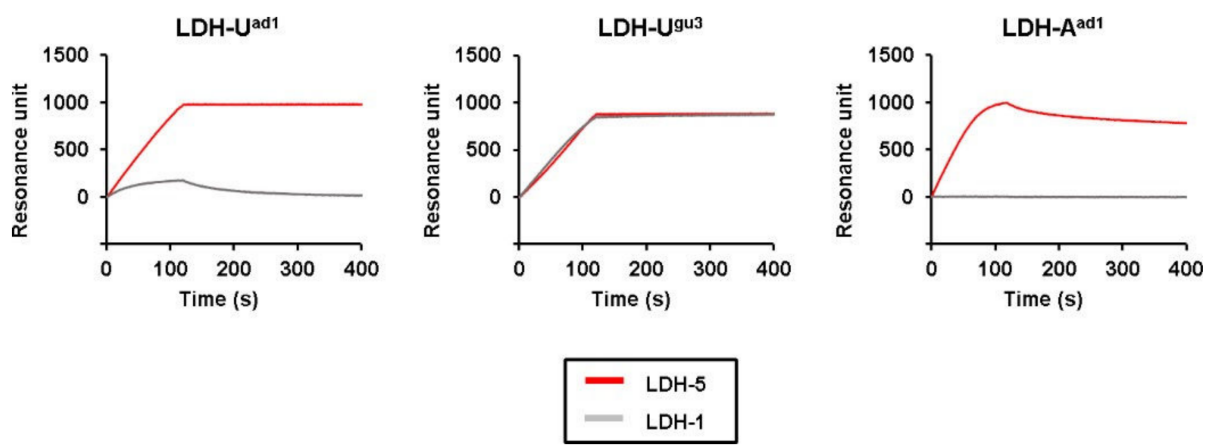

Figure A6. SPR response curve of the interaction between either LDH-5 or LDH-1 and the candidate aptamers LDH-Uad1, Ugu3, and $\mathrm{A}^{\text {ad1 }}$. LDH- 5 or LDH-1 ( $400 \mathrm{nM}$ each) were injected over the respective aptamer-immobilizing sensor chips for $120 \mathrm{~s}$ at a flow rate of $50 \mu \mathrm{L} / \mathrm{min}$. The red line represents the LDH-5 measured curve, while the gray line represents the LDH-1 recorded curves.

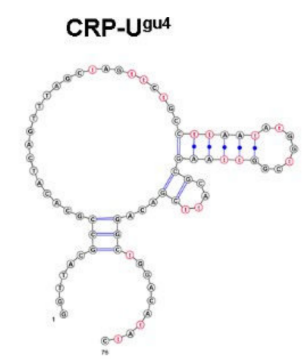

CRP-Ugu4-2

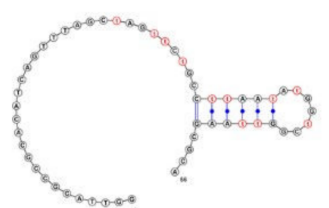

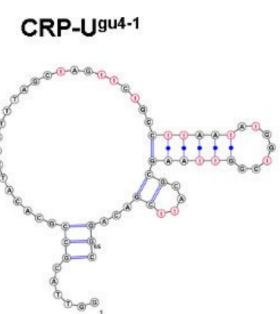

CRP-Ugu4-3

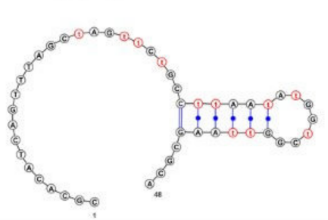

CRP-Ugu4-4

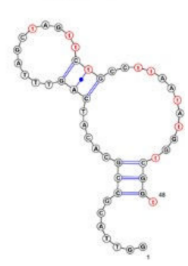

Figure A7. Predicted secondary structures of CRP-Ugu4 and truncated aptamers (Ugu4-1, Ugu4-2, Ugu4-3, and Ugu4-4) using the VALFold software and the general DNA parameters [37,38]. The letter " $\mathrm{t}$ " indicates Ugu. 


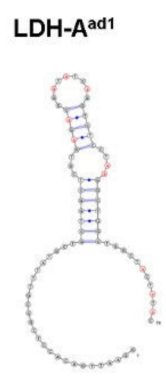

LDH-A

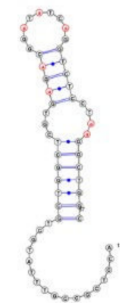

LDH-A ad1-1

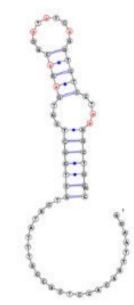

LDH-A ad1-3

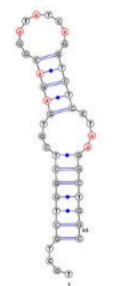

LDH-A ${ }^{\text {ad1-4 }}$

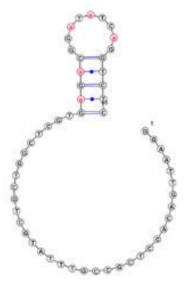

Figure A8. Predicted secondary structures of LDH-Aad1 and truncated aptamers (Aad1-1, Aad1-2, Aad1-3, and $\mathrm{A}^{\text {ad1-4}}$ ) using the VALFold software and the general DNA parameters $[37,38]$. The letter "a" indicates $\mathrm{A}^{\mathrm{ad}}$.

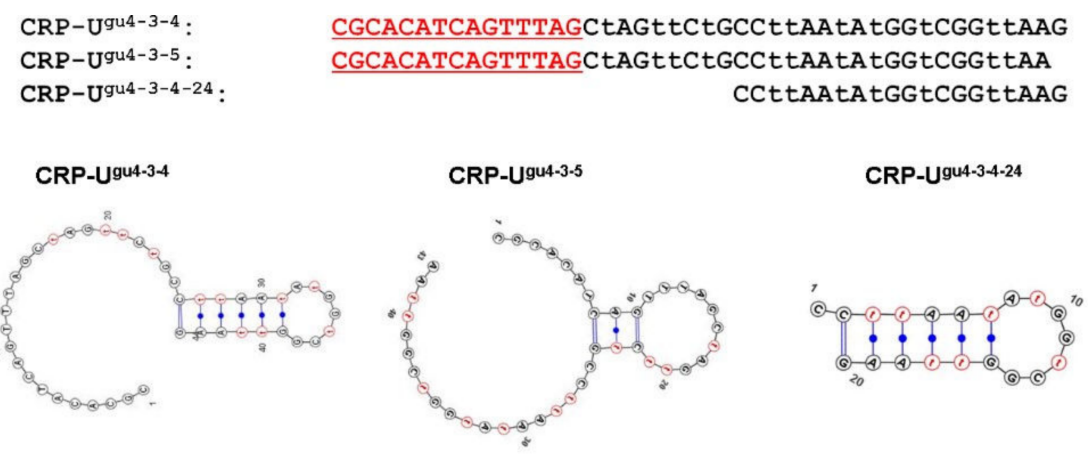

Figure A9. Predicted secondary structures of CRP-Ugu4-3 truncated sequences (CRP-Ugu4-3-4, CRP-Ugu4-3-5, and CRP-Ugu4-3-4-24) using the VALFold software and the general DNA parameters $[37,38]$. The letter " $t$ " indicates $U$ gu.

\section{References}

1. Ellington, A.D.; Szostak, J.W. In vitro selection of RNA molecules that bind specific ligands. Nature 1990, 346, 818-822. [CrossRef] [PubMed]

2. Tuerk, C.; Gold, L. Systematic evolution of ligands by exponential enrichment: RNA ligands to bacteriophage T4 DNA polymerase. Science 1990, 249, 505-510. [CrossRef] [PubMed]

3. Odeh, F.; Nsairat, H.; Alshaer, W.; Ismail, M.A.; Esawi, E.; Qaqish, B.; Bawab, A.A.; Ismail, S.I. Aptamers chemistry: Chemical modifications and conjugation strategies. Molecules 2020, 25, 3. [CrossRef] [PubMed]

4. Crivianu-Gaita, V.; Thompson, M. Aptamers, antibody scFv, and antibody Fab' fragments: An overview and comparison of three of the most versatile biosensor biorecognition elements. Biosens. Bioelectron. 2016, 85, 32-45. [CrossRef]

5. Chen, A.; Yang, S. Replacing antibodies with aptamers in lateral flow immunoassay. Biosens. Bioelectron. 2015, 71, 230-242. [CrossRef]

6. Nimjee, S.M.; White, R.R.; Becker, R.C.; Sullenger, B.A. Aptamers as therapeutics. Annu. Rev. Pharmacol. Toxicol. 2017, 57, 61-79. [CrossRef]

7. Ilgu, M.; Nilsen-Hamilton, M. Aptamers in analytics. Analyst 2016, 141, 1551-1568. [CrossRef]

8. Komarova, N.; Kuznetsov, A. Inside the black box: What makes SELEX better? Molecules 2019, $24,3598$. [CrossRef] 
9. Blind, M.; Blank, M. Aptamer selection technology and recent advances. Mol. Ther.-Nucleic Acids 2015, 4, e223. [CrossRef]

10. Sun, H.; Zu, Y. A highlight of recent advances in aptamer technology and its application. Molecules 2015, 20, 11959-11980. [CrossRef]

11. Adachi, T.; Nakamura, Y. Aptamers: A review of their chemical properties and modifications for therapeutic application. Molecules 2019, 24, 4229. [CrossRef] [PubMed]

12. Gold, L.; Ayers, D.; Bertino, J.; Bock, C.; Bock, A.; Brody, E.N.; Carter, J.; Dalby, A.B.; Eaton, B.E.; Fitzwater, T.; et al. Aptamer-based multiplexed proteomic technology for biomarker discovery. PLoS ONE 2010, 5, e15004. [CrossRef] [PubMed]

13. Kimoto, M.; Yamashige, R.; Matsunaga, K.; Yokoyama, S.; Hirao, I. Generation of high-affinity DNA aptamers using an expanded genetic alphabet. Nat. Biotechnol. 2013, 31, 453-457. [CrossRef]

14. Imaizumi, Y.; Kasahara, Y.; Fujita, H.; Kitadume, S.; Ozaki, H.; Endoh, T.; Kuwahara, M.; Sugimoto, N. Efficacy of base-modification on target binding of small molecule DNA aptamers. J. Am. Chem. Soc. 2013, 135, 9412-9419. [CrossRef]

15. Kuwahara, M.; Fujita, H.; Kataoka, Y.; Nakajima, Y.; Yamada, M.; Sugimoto, N. In situ condensation of an anti-cancer drug into fibrin gel enabling effective inhibition of tumor cell growth. Chem. Commun. 2019, 55, 11679-11682. [CrossRef] [PubMed]

16. Minagawa, H.; Onodera, K.; Fujita, H.; Sakamoto, T.; Akitomi, J.; Kaneko, N.; Shiratori, I.; Kuwahara, M.; Horii, K.; Waga, I. Selection, characterization and application of artificial DNA aptamer containing appended bases with sub-nanomolar affinity for a salivary biomarker. Sci. Rep. 2017, 7, 42716. [CrossRef]

17. Minagawa, H.; Shimizu, A.; Kataoka, Y.; Kuwahara, M.; Kato, S.; Horiii, K.; Shiratori, I.; Waga, I. Fluorescence polarization-based rapid detection system for salivary biomarkers using modified DNA aptamers containing base-appended bases. Anal. Chem. 2020, 92, 1780-1787. [CrossRef] [PubMed]

18. Kushner, I. The phenomenon of the acute phase response. Ann. N. Y. Acad. Sci. 1982, 389, 39-48. [CrossRef]

19. Pathak, A.; Agrawal, A. Evolution of C-reactive protein. Front. Immunol. 2019, 10, 943. [CrossRef]

20. Ouellet-Morin, I.; Danese, A.; Williams, B.; Arseneault, L. Validation of a high-sensitivity assay for C-reactive protein in human saliva. Brain Behav. Immun. 2011, 25, 640-646. [CrossRef]

21. La Fratta, I.; Tatangelo, R.; Campagna, G.; Rizzuto, A.; Franceschelli, S.; Ferrone, A.; Patruno, A.; Speranza, L.; De Lutiis, M.A.; Felaco, M.; et al. The plasmatic and salivary levels of IL-1 $\beta$, IL-18 and IL-6 are associated to emotional difference during stress in young male. Sci. Rep. 2018, 8, 3031. [CrossRef] [PubMed]

22. Gohel, V.; Jones, J.A.; Wehler, C.J. Salivary biomarkers and cardiovascular disease: A systematic review. Clin. Chem. Lab. Med. 2018, 56, 1432-1442. [CrossRef] [PubMed]

23. Dekker, R.L.; Lennie, T.A.; Moser, D.K.; Miller, C.S.; Ebersole, J.L.; Chung, M.L.; Campbell, C.L.; Bailey, A.; Tovar, E.G. Salivary biomarkers, oral inflammation, and functional status in patients with heart failure. Biol. Res. Nurs. 2017, 19, 153-161. [CrossRef] [PubMed]

24. Omran, A.; Ali, M.; Saleh, M.H.; Zekry, O. Salivary C-reactive protein and mean platelet volume in diagnosis of late-onset neonatal pneumonia. Clin. Respir. J. 2018, 12, 1644-1650. [CrossRef]

25. Wang, W.; Mai, Z.; Chen, Y.; Wang, J.; Li, L.; Su, Q.; Li, X.; Hong, X. A label-free fiber optic SPR biosensor for specific detection of C-reactive protein. Sci. Rep. 2017, 7, 16904. [CrossRef]

26. Castro, A.R.; Silva, S.O.; Soares, S.C. The use of high sensitivity C-reactive protein in cardiovascular disease detection. J. Pharm. Pharm. Sci. 2018, 21, 496-503. [CrossRef]

27. Liaw, C.C.; Wang, C.H.; Huang, J.S.; Kiu, M.C.; Chen, J.S.; Chang, H.K. Serum lactate dehydrogenase level in patients with nasopharyngeal carcinoma. Acta Oncol. 1997, 36, 159-164. [CrossRef]

28. Lokesh, K.; Kannabiran, J.; Rao, M.D. Salivary lactate dehydrogenase (LDH)—A novel technique in oral cancer detection and diagnosis. J. Clin. Diagn. Res. 2016, 10, ZC34-ZC37. [CrossRef]

29. Urbańska, K.; Orzechowski, A. Unappreciated role of LDHA and LDHB to control apoptosis and autophagy in tumor cells. Int. J. Mol. Sci. 2019, 20, 2085. [CrossRef]

30. Malicka, B.; Skoskiewicz-Malinowska, K.; Kaczmarek, U. Salivary lactate dehydrogenase and aminotransferases in diabetic patients. Medicine 2016, 95, e5211. [CrossRef]

31. Joshi, P.S.; Golgire, S. A study of salivary lactate dehydrogenase isoenzyme levels in patients with oral leukoplakia and squamous cell carcinoma by gel electrophoresis method. J. Oral Maxillofac. Pathol. 2014, 18, S39-S44. [CrossRef] [PubMed] 
32. Saluja, T.S.; Spadigam, A.; Dhupar, A.; Syed, S. Equating salivary lactate dehydrogenase (LDH) with LDH-5 expression in patients with oral squamous cell carcinoma: An insight into metabolic reprogramming of cancer cell as a predictor of aggressive phenotype. Tumor Biol. 2016, 37, 5609-5620. [CrossRef] [PubMed]

33. Jurisic, V.; Radenkovic, S.; Konjevic, G. The actual role of LDH as tumor marker, biochemical and clinical aspects. Adv. Exp. Med. Biol. 2015, 867, 115-124. [PubMed]

34. Nonomiya, Y.; Noguchi, K.; Katayama, K.; Sugimoto, Y. Novel pharmacological effects of poly (ADP-ribose) polymerase inhibitor rucaparib on the lactate dehydrogenase pathway. Biochem. Biophys. Res. Commun. 2019, 510, 501-507. [CrossRef]

35. Shangguan, D.; Tang, Z.; Mallikaratchy, P.; Xiao, Z.; Tan, W. Optimization and modifications of aptamers selected from live cancer cell lines. Chembiochem 2007, 8, 603-606. [CrossRef]

36. He, X.; Guo, L.; He, J.; Xu, H.; Xie, J. Stepping library-based post-SELEX strategy approaching to the minimized aptamer in SPR. Anal. Chem. 2017, 89, 6559-6566. [CrossRef]

37. Akitomi, J.; Kato, S.; Yoshida, Y.; Horii, K.; Furuichi, M.; Waga, I. Valfold: Program for the aptamer truncation process. Bioinformation 2011, 7, 38-40. [CrossRef]

38. SantaLucia, J. A unified view of polymer, dumbbell, and oligonucleotide DNA nearest-neighbor thermodynamics. Proc. Natl. Acad. Sci. USA 1998, 95, 1460-1465. [CrossRef]

39. Huang, C.J.; Lin, H.I.; Shiesh, S.C.; Lee, G.B. Integrated microfluidic system for rapid screening of CRP aptamers utilizing systematic evolution of ligands by exponential enrichment (SELEX). Biosens. Bioelectron. 2010, 25, 1761-1766. [CrossRef]

40. Wang, M.S.; Black, J.C.; Knowles, M.K.; Reed, S.M. C-reactive protein (CRP) aptamer binds to monomeric but not pentameric form of CRP. Anal. Bioanal. Chem. 2011, 401, 1309-1318. [CrossRef]

41. Tsao, S.M.; Lai, J.C.; Horng, H.E.; Liu, T.C.; Hong, C.Y. Generation of aptamers from a primer-free randomized ssDNA library using magnetic-assisted rapid aptamer selection. Sci. Rep. 2017, 7, 45478. [CrossRef] [PubMed]

42. Eid, C.; Palko, J.W.; Katilius, E.; Santiago, J.G. Rapid slow off-rate modified aptamer (SOMAmer)-based detection of C-reactive protein using isotachophoresis and an ionic spacer. Anal. Chem. 2015, 87, 6736-6743. [CrossRef] [PubMed]

43. Thompson, D.; Pepys, M.B.; Wood, S.P. The physiological structure of human C-reactive protein and its complex with phosphocholine. Structure 1999, 7, 169-177. [CrossRef]

44. Poli, G.; Granchi, C.; Aissaoui, M.; Minutolo, F.; Tuccinardi, T. Three-dimensional analysis of the interactions between hLDH5 and its inhibitors. Molecules 2017, 22, 2217. [CrossRef] [PubMed]

45. Webber, J.; Stone, T.C.; Katilius, E.; Smith, B.C.; Gordon, B.; Mason, M.D.; Tabi, Z.; Brewis, I.A.; Clayton, A. Proteomics analysis of cancer exosomes using a novel modified aptamer-based array (SOMAscan ${ }^{\mathrm{TM}}$ ) platform. Mol. Cell. Proteom. 2014, 13, 1050-1064. [CrossRef] [PubMed]

46. Mafessoni, T.P.; Mazur, C.E.; Amenábar, J.M. Salivary lactate dehydrogenase (LDH) as a tool for early diagnosis of oral cancer in individuals with Fanconi anemia. Med. Hypotheses 2018, 119, 29-31. [CrossRef]

47. Idili, A.; Arroyo-Currás, N.; Ploense, K.L.; Csordas, A.T.; Kuwahara, M.; Kippin, T.E.; Plaxco, K.W. Seconds-resolved pharmacokinetic measurements of the chemotherapeutic irinotecan in situ in the living body. Chem. Sci. 2019, 10, 8164-8170. [CrossRef]

48. Peeters, M.; Jiménez-Monroy, K.L.; Libert, C.; Eurlings, Y.; Cuypers, W.; Wackers, G.; Duchateau, S.; Robaeys, P.; Nesladek, M.; Van Grinsven, B.; et al. Real-time monitoring of aptamer functionalization and detection of Ara $\mathrm{H} 1$ by electrochemical impedance spectroscopy and dissipation-mode quartz crystal microbalance. J. Biosens. Bioelectron. 2014, 5, 155.

49. Van Grinsven, B.; Eersels, K.; Peeters, M.; Losada-Pérez, P.; Vandenryt, T.; Cleij, T.J.; Wagner, P. The heat-transfer method: A versatile low-cost, label-free, fast, and user-friendly readout platform for biosensor applications. ACS Appl. Mater. Interfaces 2014, 6, 13309-13318. [CrossRef]

50. Li, H.; Somerson, J.; Xia, F.; Plaxco, K.W. Electrochemical DNA-based sensors for molecular quality control: Continuous, real-time melamine detection in flowing whole milk. Anal. Chem. 2018, 90, 10641-10645. [CrossRef]

51. Idili, A.; Parolo, C.; Ortega, G.; Plaxco, K.W. Calibration-free measurement of phenylalanine levels in the blood using an electrochemical aptamer-based sensor suitable for point-of-care applications. ACS Sens. 2019, 4, 3227-3233. [CrossRef] [PubMed] 
52. Kasahara, Y.; Irisawa, Y.; Fujita, H.; Yahara, A.; Ozaki, H.; Obika, S.; Kuwahara, M. Capillary electrophoresis-systematic evolution of ligands by exponential enrichment selection of base- and sugar-modified DNA aptamers: Target binding dominated by 2'-O,4'-C-methylene-bridged/locked nucleic acid primer. Anal. Chem. 2013, 85, 4961-4967. [CrossRef] [PubMed]

53. Minagawa, H.; Kataoka, Y.; Kuwahara, M.; Horii, K.; Shiratori, I.; Waga, I. A high affinity modified DNA aptamer containing base-appended bases for human $\beta$-defensin. Anal. Biochem. 2020,594, 113627. [CrossRef] [PubMed]

(C) 2020 by the authors. Licensee MDPI, Basel, Switzerland. This article is an open access article distributed under the terms and conditions of the Creative Commons Attribution (CC BY) license (http://creativecommons.org/licenses/by/4.0/). 